\title{
Från behandlingsideologi till nyklassicism ${ }^{1}$
}

\author{
Af Dag Victor ${ }^{2}$
}

\begin{abstract}
This article is based on notes for an oral presentation made at the 100th anniversary of Swedish Kriminalistföreningen in the autumn of 2011. The Association was formed at a time when the so-called treatment ideology began to grow strong in Swedish criminal policy. The peak of this ideology was reached in the 1950s, but it still dominated criminal policy when the new Criminal Code came into force in 1965. From the late 1960s, however, it was subject to increasing criticism. From the 1980s, the treatment-oriented criminal policy was also gradually replaced by a neo-classical criminal policy with emphasis on concepts such as censure, penalty and proportionality. Of importance for this development was that research on treatment did not support the opinion that treatment was an effective tool to reduce crime. However, the article argues, with classical criminal law as a background, that the criticism was mainly based on the fact that the individual in a treatment-oriented system is not seen as a responsible subject but as an irresponsible object that may be subject to coercion as a means to achieve social goals or advance his "own interests (paternalistic intervention). The concept of guilt, which was central in classical criminal law, is rejected as pure metaphysics. In neoclassical criminal law the concept of guilt has been restored. However, there are still many remnants of older criminal policy in both legislation and public debate.
\end{abstract}

Inom rättens hela område finns det inte något begrepp som tillnärmelsevis kan mäta sig med straffbegreppet i kulturhistorisk betydelse, inget annat begrepp är som detta i varje tid en trogen spegelbild av folkets tanke- och känsloliv, en mätare av dess bildningsnivå, inget annat visar som detta alla faser i folkets sedliga utveckling, mjukt och smidigt som vax i vilket varje intryck sätter spår.

Rudolf Jehring 1867

* Title in English: From treatment ideology to neoclassicism. 
1. Man kan naturligtvis ha olika skäl för att intressera sig för straffrätt. För egen del beror mitt intresse främst på att jag inte vet någon annan samhällsföreteelse som bättre återspeglar ett samhälles sociala och moraliska läge. Straffet är statens yttersta maktmedel. I förutsättningarna för dess användning koncentreras för samhället fundamentala frågor om makt och vanmakt och rätt och orätt. I grunden är kriminalpolitikens viktigaste fråga knappast hur vi mest effektivt ska bekämpa brottslighet utan vilka medel som vi anser oss vara berättigade att använda för denna uppgift.

2. Straffrättens utformning växlar alltså i betydande grad inte bara mellan olika länder utan också över tid. De två olika grundkonceptioner av straffrätt som återspeglas i rubrikens båda termer kan i grova drag sägas täcka utvecklingen av svensk straffrätt under de 100 år som Svenska kriminalistföreningen verkat. Ska man säga något om den utvecklingen kan det emellertid vara lämpligt att utgå från en annan sorts straffrätt - den klassiska - som behandlingsideologin reagerade mot och nyklassicismen återknöt till.

3. Vad vi vanligen menar med den klassiska straffrätten är den form av straffrätt som utvecklades i Tyskland i början av 1800-talet (med P. J. A. von Feuerbach (1775-1833) som portalfigur). Ideologiskt går dock dess rötter längre tillbaka i tiden. Den klassiska straffrätten framstår som en produkt av upplysningstiden och dess reaktion mot tidigare ordning med maktkoncentration, hemliga rättegångar, tortyr, grymma straff etc., en ordning enligt vilken rätten alltid ytterst vilade i spjutstångs ände. Reaktionen var i första hand av statsrättslig karaktär. Mot den tidigare ordningen ställdes krav på maktdelning, på fria och självständiga domstolar, på lagstöd för utdömande av straff (legalitet), på proportionalitet som begränsning av straffens stränghet. Det var under denna tid som de ideal som vi känner igen under rubriker som rättsstatlighet och skydd för de mänskliga rättigheterna utvecklades. Som paroll för dessa ideal används ofta Johann H. Pestalozzis (1746-1827) berömda ord om att vad vi vill inte är att människan ska förstatligas utan tvärtom att staten ska förmänskligas.

4. Ett ytterligare utmärkande drag för den klassiska straffrätten är utvecklingen från äldre effektstraffrätt till skuldstraffrätt. Skuldprincipen (nulla poena sine culpa) etableras som en viktig begränsande faktor i straffrätten. En förklaring till att principen tidigare inte hade samma betydelse kan spåras i att begreppen skuld, orsak och klander, såväl i svenskan som i andra språk, har ett etymologiskt mycket nära samband. Begreppen ingick ursprungligen i samma betydelsefält. 
Orsaksbegreppet var inte, som idag, naturvetenskapligt präglat utan var i huvudsak synonymt med skuldbegreppet. Och skuldbegreppet var inte, som dagens juridiska skuldbegrepp, exklusivt knutet till förutsättningarna för personligt ansvar. Även om vi bortser från arvsynden hade skuldbegreppet ett betydligt vidare tilllämpningsområde än så. Och både orsakande och skuld kunde utgöra underlag för klander.

5. Rättssystematiskt kommer skuldprincipen till uttryck genom uppdelningen av brottsbegreppet $\mathrm{i}$ en objektiv och en subjektiv sida där en förutsättning för ansvar är att den subjektiva (uppsåt eller oaktsamhet) »täcker« den objektiva. Uppdelningen blir möjlig genom att orsaks- och skuldfrågorna systematiskt behandlas som två helt skilda frågor. Den klassiska straffrätten bygger i detta hänseende på att det $\mathrm{i}$ grunden finns en skillnad mellan människorna och naturen i övrigt. Medan naturen är underkastad blinda orsakslagar har människorna en fri vilja. Det är den fria viljan som är grunden för ansvarsförmågan. Härigenom har också frågan om klander i allmänhet kommit att uppfattas som exklusivt knutet till skuldbegreppet.

6. Den klassiska straffrätten kan i detta hänseende sägas vila på upplysningshumanismens uppfattning om människan och naturen och förhållandet mellan dem en uppfattning som i och för sig har djupare historiska rötter och också kom till uttryck i renässanshumanismen. Ett klassiskt utryck för uppfattningen är den s.k. Humanismens höga visa av Giovanni Pico della Mirandola (1463-1494): Varken en bestämd ort eller en gestalt som är din egen eller någon uppgift som är säregen för dig har vi givit dig, Adam, på det att du efter ditt beslut och enligt din åsikt skall få och äga den ort, den gestalt, de uppgifter du önskar. Andra varelsers natur begränsas inom av oss föreskrivna lagar. Du är av inga gränser instängd, utan skall fastställa dem själv med din vilja $i$ vars hand jag lagt dig. Mitt $i$ världen har jag ställt dig, för att du därifrån såmycket lättare skall kunna skåda runt omkring dig allt som finns $i$ världen. Varken himmelsk eller jordisk, varken dödlig eller odödlig har vi gjort dig, på det att du liksom din egen skulptör och formare fritt och ärofullt må kunna ge dig den gestalt du helst vill ha. Du skall ha makt att degenerera till lägre former som är djuriska, du skall ha makt att enligt din själs beslut regenereras till de högre former som är gudomliga.

7. Men i förlängningen av upplysningstidens rationalism och förnuftstro ligger också ett ifrågasättande av den särställning för människan i förhållande till naturen i övrigt som ligger till grund för den klassiska straffrätten. Är inte också män- 
niskan som en del av naturen underkastad de vanliga orsakslagarna? Är då inte den fria viljan blott en chimär? Om man bejakar detta förlorar därmed också begreppen skuld och klander meningsfull referens. Sådana uppfattningar gjorde sig alltmer gällande under senare delen av 1800-talet och var på det kriminalpolitiska fältet vägledande för exempelvis den s.k. positiva skolan med Cesare Lombroso (1835-1909) som inspiratör och Enrico Ferri (1856-1929) som främste företrädare. Skolan sade sig vilja befria brottslingarna från skuld och hela rättsväsendet från föråldrade och otympliga principer och ersätta dessa med diagnoser och orsaksförklaringar. Voluntarism skulle ersättas av determinism, ansvar av kausalitet och straff av skydd. I den positiva skolans värld var brottslingen inte ett fritt handlande subjekt utan ett passivt objekt för de naturliga orsakslagarna.

8. Synsätt av detta slag fick från början av 1900-talet allt större genomslag i den svenska praktiska kriminalpolitiken och utgjorde grunden för den s.k. behandlingsideologin. Som utvecklingens främste ideolog framstår rättspsykiatrikern Olof Kinberg (1873-1960) medan Karl Schlyter (1879-1959) var den främste praktiske reformatorn. Ett viktigt inslag i utvecklingen var att skuldbegreppet stämplades som ren metafysik (samtidigt som de subjektiva rekvisiten gavs större självständig betydelse för kriminaliseringens omfattning genom exempelvis fareoch försöksbrottskriminaliseringar). Det kriminalpolitiska intresset försköts från brottet till brottslingen. Straffet (påföljden) borde anpassas inte efter brottet utan efter vad som krävs för att förebygga nya brott. På den grunden utvecklas det efter olika brottslingskategorier differentierade påföljdssystemet (med särskilda påföljder för unga, för tillfällighetsbrottslingar, för behandlingsbara och för oförbätterliga).

9. Utvecklingens höjdpunkt kan sägas ha nåtts i och med att Strafflagberedningen (under ordförandeskap av Schlyter) la fram sitt slutbetänkande (SOU 1956:55) Skyddslag. I betänkandet föreslås att straffbegreppet helt ska avskaffas och att någon skillnad i princip inte ska göras mellan »vård « till följd av brott och annan vård. Det är också här som grunden läggs för avskaffandet av det på skuldbegreppet (ansvarsförmågan) byggande tillräknelighetsbegreppet - ett avskaffande som ställer Sverige i en särställning i förhållande till de länder som vi i allmänhet önskar jämföra oss med när det gäller det straffrättsliga systemets struktur och innehåll.

10. Utvecklingen skedde inte utan debatt. Strafflagberedningens slutbetänkande föranledde ett intensivt meningsutbyte (delvis återgiven i skriften Aktuell debatt 
om BROTT och STRAFF, 1957) med kraftig polarisering. Debatten rörde emellertid inte skuldbegreppets eventuella berättigande utan vilken av preventionshänsynen - de allmänpreventiva eller de individualpreventiva - som borde tillmätas störst betydelse. Att syftet med brottspåföljder var att förebygga brott rådde ingen oenighet om. Oenigheten gällde på vilket sätt detta bäst gjordes. Det var också i den delen som det fanns politiska motsättningar.

11. År 1962 antogs den nya brottsbalken som trädde i kraft år 1965. Det var ett jättelikt lagstiftningsprojekt som dock gick i filttofflor genom riksdagen. Motsättningarna löstes i huvudsak genom pragmatiska kompromisser. Någon särskild skyddsbalk blev det inte. Strafflagen ersattes i stället av en brottsbalk. Straffbegreppet behölls för böter och fängelse men avskaffades för andra påföljder för brott. Och när det gäller grunderna för bestämmande av påföljd slutade det hela $\mathrm{i}$ den berömda kompromissen i 1 kap $7 \S$ brottsbalken; "Vid val av påföljd skall rätten, med iakttagande av vad som kräves för att upprätthålla allmän laglydnad, fästa särskilt avseende vid att påföljden skall vara ägnad att främja den dömdes anpassning $i$ samhället.« Påföljden skulle alltså inte bestämmas med utgångspunkt i brottet utan utifrån en »prognos« över olika påföljders effekter. Formellt gällde bestämmelsen endast påföljdsvalet men enligt förarbetena kunde den också ge viss vägledning för straffmätningen.

12. I början av 1970-talet börjar den kriminalpolitik som ligger bakom brottsbalken, dvs behandlingsideologin, att utsättas för mer allmän kritik. Återigen ger kriminologin bränsle åt kritiken. Den moderna behandlingsforskningen visar inget stöd för att det skulle vara möjligt att minska brottsligheten genom behandlingsinsatser. Resultaten tyder snarare på att det finns en »negativ individualprevention«; ju mer man ingriper dess sämre går det. Detta är särskilt tydligt när det gäller frihetsberövanden där »institutionaliseringens« negativa effekter uppmärksammas. Inte heller ger forskningen något stöd för den allmänpreventiva hypotesen att justeringar av ingripandegraden vid olika brott skulle vara ett verksamt medel för påverka kriminalitetsnivåerna. Allt fler förordar efterhand att det behandlingsideologiska påföljdssystemet ska överges och ersättas av en »nyklassisk straffrätt« med betoning av begrepp som klander, straffvärde och proportionalitet.

13. Den egentliga grunden för den nyklassiska kritiken av »behandlingsideologin « (och andra rent preventionistiska straffteorier) är emellertid inte den bristande effektiviteten i sig. Vad kritiken främst inriktar sig på är i stället att individen i ett behandlingsorienterat system inte betraktas som ett ansvarigt subjekt 
utan som ett oansvarigt objekt som kan utsättas för tvång som medel för att uppnå samhälleliga mål eller i »eget« intresse (paternalistiska ingripanden). Kort sagt kan det »nyklassiska« sägas ligga i en återanvändning av skuldprincipen som begränsande faktor för rättssystemet. Däremot betonas i såväl Nytt straffsystem (Brå rapport 1977:7) som i fängelsestraffkommitténs betänkande (SOU 1986:14) Påföljd för brott och den på det betänkandet grundade prop. 1987/88:120 om straffmätning och påföljdsval (de centrala »nyklassiska« dokumenten) att »det är av avgörande betydelse för möjligheterna till en human och meningsfull kriminalvård att man behåller ambitionerna att inom ramen för de ådömda påföljderna så långt det är möjligt genom stöd och hjälp söka underlätta de dömdas återanpassning i samhället«.

14. Idag skulle det kunna synas som att det nyklassiska synsättet är allmänt accepterat och okontroversiellt. De kriminalpolitiska skiljelinjerna går främst på andra områden än de som gäller skuld som ansvarsförutsättning och iakttagande av proportionalitet mellan brott och straff. Den senaste större straffrättsliga reformen (prop. 2009/10:147 Skärpta straff för allvarliga våldsbrott m.m.) grundade sig exempelvis på ett betänkande (SOU 2008:85) med den programmatiska titeln Straff $i$ proportion till brottets allvar. I propositionen slås också redan inledningsvis fast att den »den grundläggande utgångspunkten för påföljdsbestämningen är och ska även fortsättningsvis vara brottets allvar. Straffet ska återspegla hur allvarligt, klandervärt, det brott som den tilltalade döms för är«. I stort sett samma formulering används också i direktiven till Påföljdsutredningen (Ju 2009:11) vars betänkande kan antas komma att bilda underlag för nästa större reform av påföljdssystemet. Nog för att det finns olika uppfattningar om dessa reformer men någon opposition mot »den grundläggande utgångspunkten« förekommer knappast.

15. Fortfarande lyser dock det straffrättsliga skuldbegreppet i allmänhet med sin frånvaro i den officiella kriminalpolitiken. Det används inte i lagtext och återfinns exempelvis inte i något av de nyss nämnda dokumenteten (om man undantar betänkandets redogörelse för främmande rätt där det av naturliga skäl återkommer fortlöpande). När det i betänkandets överväganden talas om »skuldfrågan« avses inte den straffrättsliga »skulden« utan den avvikande straffprocessuella som också omfattar brottets objektiva sida. »Skuldfrågan《 motsvarar alltså vad som från straffrättslig utgångspunkt skulle betecknas som »ansvarsfrågan« till skillnad från »påföljdsfrågan« (som enligt den straffprocessuella terminologin däremot utgör en del av »ansvarsfrågan«). 
16. I viss mån kan skuldens fortsatta frånvaro som kriminalpolitiskt begrepp förklaras av att det inte heller används i lagtext. Fängelsestraffkommittén föreslog på sin tid i betänkandet Påföljd för brott att "gärningsmannens skuld sådan den kommit till uttryck i gärningen« skulle ingå som ett led i lagtextens beskrivning av vad som avsågs med en gärnings straffvärde. Något förbehållslöst accepterande av skuldprincipen gav dock detta förslag inte uttryck för. Tvärtom förklarade kommittén att den var medveten om den livliga diskussion som skuldbegreppet gett upphov till i straffrättslitteraturen och att avsikten inte var »att på något vis ta ställning till olika filosofiska frågor kring skuldbegreppet utan vi använder det $\mathrm{i}$ en juridisk-teknisk mening«. I propositionen försvann emellertid skuldbegreppet från lagtexten med konstaterandet att även om kommitténs avsikt med att använda skuldbegreppet inte torde »ha varit annan än att finna en kort sammanfattande beteckning på olika till gärningsmannen hänförliga faktorer av betydelse för straffvärdebedömningen« så hade kommitténs förslag i denna del »mött åtskilliga invändningar vid remissbehandlingen«.

17. Karaktären av de invändningar som riktades mot kommitténs förslag kan illustreras med ett citat från Ivar Strahls (1899-1987) inflytelserika bok Den svenska kriminalpolitiken som utkom i fem upplagor mellan år 1961 och 1970. I boken säger Strahl, som knappast kan betecknas som en extrem behandlingsideolog, bl.a. följande: «Att hävda att strafflagen och dess tillämpning skulle bygga på tanken att brottslingen ådragit sig skuld synes icke vara stort bättre än att bygga på en fiktion, när man vet hur olika förutsättningarna för att hålla sig ostrafflig är bland människorna. ... Ju klarare man inser detta, desto svårare är det att våga påstå, att de människor som gjort sig skyldiga till brott därmed ådragit sig en skuld som kunde konstateras och giorde det rättvist att de bestraffas på visst sättr.

18. I själva verket lever också stora delar av den av behandlingsidologin influerade kriminalpolitiken kvar. Påföljdssystem och påföljdsval är fortfarande präglade av prognostänkande och strävan efter till gärningsmannen anpassade påföljder. Bestämmelserna i 34 kap. brottsbalken om sammanträffande av brott och förändring av påföljd är fortfarande i huvudsak uppbyggda på (och endast begripliga utifrån) en behandlingsideologisk grund. Som ett uttryck för en sådan kriminalpolitik framstår också den tolkning som Högsta domstolen gjorde i NJA 1973 s. 590 av bestämmelsen om självförvållat rus i 1 kap 2 § första stycket brottsbalken. Tolkningen innebar att kravet på uppsåt eller oaktsamhet (skuld) i viss mån skulle efterges vid självförvållat rus och liknande tillstånd. När Högsta domstolen 
nyligen ställde sig (NJA 2011 s. 563) avvisande till ett fortsatt sådant avsteg från kravet på skuld var det inte något som alla uppfattade som naturligt eller önskvärt. Även om avgörandet välkomnades på många håll möttes det också av häftig kritik från bl.a. ett par i äldre tiders kriminalpolitik fostrade akademiker (SvD den 1 november 2011) som menade att avgörandet innebar att ett grunddrag i svensk straffrätt sopades bort och att berusning upphöjdes till en ursäkt för brott genom inte efterge kravet på skuld.

19. Men den viktigaste kvarlevan från äldre kriminalpolitik är ändå den svenska avsaknaden av tillräknelighet som ett krav för straffansvar. Frågan har i princip utretts oavbrutet sedan brottsbalken trädde i kraft. Här är inte platsen att följa den vindlande historien. År 2002 var det emellertid många som trodde att en ändring nu snart skulle komma. Då lade Psykansvarskommittén fram sitt betänkande (SOU 2002:3) Psykisk störning, brott och ansvar. Den eniga parlamentariska kommittén föreslog, utan några avvikande meningar från sakkunniga och experter, att tillräknelighet skulle återinföras som ansvarsförutsättning. Om skuldprincipen anförde kommittén följande: »Sedan den liberala rättsstatens genombrott $i$ samband med den franska revolutionen år 1789 har $i$ alla moderna rättsstater skuldprincipen intagit en central position inom straffrätten. Kravet på tillräknelighet eller ansvarsförmåga utgör en av grundbultarna $i$ sådana rättssystem, något som också visar sig $i$ det faktum att tillräknelighetskravet är en förutsättning för straffrättsligt ansvar och ses som ett rättsstatligt grundkrav $i$ samtliga jämförbara rättssystem såväl i Europa som i övriga världen. ... Om man inte förfäktar synen att alla våra gärningar är helt förutbestämda och att moraliskt ansvar därmed är en illusion, anses moraliskt ansvar för en gärning som lett till en viss icke önskvärd följd kräva att gärningsmannen orsakat följden, att han $i$ någon mening valt att utföra gärningen trots alternativa valmöjligheter, att hans val var någorlunda medvetet ("var vid sina sinnens fulla bruk«) samt att han någorlunda visste och hade förmåga att förstå vilka konsekvenser som gärningen skulle leda till. De straffrättsliga bestämmelserna om personligt ansvar och straff kan $i$ många stycken ses som en $i$ demokratisk ordning beslutad och därigenom formaliserad samling moralregler. Straffansvar torde $i$ botten alltid förutsätta moraliskt ansvar, medan det omvända förhållandet inte gäller."

20. Idag har det gått snart tio år sedan Psykansvarskommittén la fram sitt betänkande. Ännu har det inte lett till någon »större reform«. I stället sitter nu en ny utredning, Psykiatrilagsutredningen, som tillsattes år 2008. I direktiven sägs att det ska vara en utgångspunkt för utredarens arbete att en större reform med ut- 
gångspunkt i Psykansvarskommitténs förslag (SOU 2002:3) när det gäller psykiskt störda lagöverträdare kommer att genomföras. Enligt de ursprungliga direktiven skulle uppdraget redovisas senast den 1 juni 2010. Tiden har därefter i omgångar skjutits upp och nu gäller att uppdraget ska redovisas senast den 15 december 2011. Väntan har varit lång men förhoppningsvis ska vi då få se något som inom inte alltför lång tid kan leda till att också Sverige kan uppfylla vad som enligt Psykansvarskommittén »ses som ett rättsstatligt grundkrav i samtliga jämförbara rättssystem såväl i Europa som i övriga världen «. ${ }^{3}$

\section{Noter}

1. Artikeln är, utan närmare bearbetning, baserad på stolpar till ett anförande vid Svenska kriminalistföreningens 100-årsjubileum den 10 november 2011.

2. Dag Victor är f.d. justitieråd (ledamot av Högsta domstolen), ledamot i Lagrådet och f.d. ordförande i Svenska kriminalistföreningen.

3. I skrivande stund har den 15 december 2011 passerats. Någon utredning har dock inte lagts fram. Enligt vad som anges på Statens offentliga utredningars webbplats gäller numera att utredningen beräknas avsluta sitt arbete den 30 mars 2012. 